\title{
Asturias en la etapa final del antiguo régimen
}

\author{
por Miguel ARTOLA Gallego \\ Catedrático de la Universidad de Salamanca
}

El conocimiento de las estructuras de diverso orden que dan su perfil característico a la España del Antiguo Régimen no ha sido hasta la fecha objeto de investigación sistemática. Incluso cuando se trata de obras generales sobre la época y la totalidad del país como las muy estimables de Desdevises du Dezert, Domínguez Ortiz o Herr predomina una técnica que podríamos llamar de muestreo. En lugar de una descripción exaustiva y en la medida de lo posible cuantificada nos encontramos fundamentalmente ante informaciones aisladas, difíciles de reducir a términos homogéneos, dado que proceden de fuentes muy diversas y que desgraciadamente - con la única excepción de los censos- no cubren sino zonas aisladas de la realidad histórica. El testimonio de un viajero, los datos con frecuencia asistemáticos de una u otra publicación contemporánea constituyen las fuentes preferentes, testimonios que sirven de base a una generalización que sólo podrá ser superada cuando equipos enteros de estudiosos hayan revisado y destilado la fabulosa documentación aún no utilizada, al menos sistemáticamente, para el estudio del siglo XVIII.

Las líneas que siguen, más que un cuadro exhaustivo de la estructura 
interna de una región, trabajo de mayor empeño y tiempo, tratan de presentar un esquema del cual no todos los puntos tendrán un igual desarrollo, esquema que luego de completado nos ofrecería un conocimiento de la realidad y sobre todo nos descubriría problemas que en el momento actual apenas si sospechamos.

Mientras la nuda realidad geográfica - situación, orografía, etc.puede considerarse inmutable, todo cuanto tiene relación con el asentamiento del hombre sobre la tierra necesita ser reconstruido por la investigación, y antes de comprender la evolución histórica necesitamos conocer con la mayor precisión las cifras de la población, sus formas de asentamiento, tanto en el aspecto material como en el político-administrativo, las circunstancias económicas de su existencia o lo que es lo mismo los modos de producción de bienes, y todo ello, como antes dije, y en la medida de lo posible, cuantificado.

El Principado de Asturias en el siglo xvir tiene unos límites que coinciden sustancialmente con la actual provincia, aunque las divisiones decimonónicas aumentaron su territorio a costa de las zonas limítrofes de la provincia de Burgos, que perdió las 24 feligresías que integran los ayuntamientos de la Peñamellera y Ribadedeva. Madoz estima constituían el $0,62 \%$ de la población de esta última provincia. La extensión del Principado, según el Censo de la riqueza territorial $e$ industrial de España en el año 1799, era de 3081/2 leguas cuadradas, ocupadas por una población que para finales del siglo XviII es conocida con relativa exactitud dada la coincidencia de los testimonios. El Estado general de la población de España en los años de 1768 y 1769 recogido en el censo de 1789 nos proporciona la cifra de 400.161 habitantes. El censo de 1787 los reduce a 347.776 y diez años después el nuevo recuento pone la población en 364.283 habitantes, que formarían 72.848 familias, dato que se repetirá en el Censo de la riqueza y en el Diccionario de Hacienda de Canga Argüelles. El Diccionario geográfico universal, que habitualmente y por lo que respecta a España se limita a transcribir lo que dice Miñano en el suyo, nos da la cifra total, que éste omitió, de 380.000 habitantes. Las cifras correspondientes a la primera mitad del siglo XIX recogidas por Madoz, reflejaban por el contrario tales diferencias que no pueden ser integradas en un proceso de desarrollo sin rechazar alguno de los testimonios.

La proporción que guarda su población con la general de España es de $4,30 \%$ en $1768 / 69$, que descendió a un $3,3 \%$ en 1787 para alcanzar un 
3,4\% diez años después. Madoz, por su parte, llega en virtud de cálculo que no explica, a un porcentaje constante de $3,65 \%$, que ui iliza para extrapolar datos que las fuentes no le proporcionan. Este corficiente aparece ligeramente aumentado al incluir, según vimos, el 0,62\% de la provincia de Burgos, ${ }^{1}$ por lo que puede considerarse muy próximo al anterior. Las cifras recogidas por Miñano para cada uno de los centrons de población, pese a ser incompletas y no concordar en algún caso con los datos de Canga Argüelles, manifiestan no ya un crecimiento vegeta. tivo, sino una sensible tendencia descendente que por el momento no sabemos si ha de atribuirse a un cambio de la coyuntura demográfica debido a la crisis de comienzos de siglo o a la utilización de otras fuentes de información. ${ }^{2}$

La población considerada hasta ahora cuantitativamente compone grupos sociales precisamente caracterizados en virtud de sus estatutos jurídicos, personales o locales. En 1787 un 32,8\% de la población asturiana disfrutaba de los privilegios inherentes a la condición nobiliaria, y Ios 114.274 hidalgos asturianos constituyen el $23,7 \%$ de la totalidad del estamento. Junto a esta cifra los eclesiásticos constituyen un pequeño sector en que los propiamente religiosos no pasan de 2.656 individuos, que forman un $0,8 \%$ del total de la población y se reparten en los siguientes estados.

Clero secular

Curas

Beneficiados

Tenientes de cura

Ordenados a título de patrimonio ........

Ordenados de menores

Clero regular

Religiosos

Religiosas

(1) «En la provincia de Oviedo figura toda la población de la antigua Asturias más un 0,62\% de la de Burgos: buscada en varios datos la proporción de los pueblos que forman la provincia de Oviedo con el resto de España, aparece ser el 3,65\%\% (Diccionario... Oviedo)

(2) El reparto de la población en el Principado se recoge en el apéndice 1. 
Clasificados en sectores sociales, hallamos una preeminencia decisiva del elemento primario con 60.986 individuos, de los que únicamente 7.036 son jornaleros. El sector industrial se reduce a 3.472 con sólo 112 fábricas, mientras el terciario asciende a 10.459 individuos, de los que un tercio son funcionarios, estudiantes o se dedican a actividades ralacionadas con la justicia (abogados, escribanos), un décimo son servidores de la Iglesia y el resto, 6.141, son criados, circunstancia que explica tan inusitado desarrollo del sector terciario.

Otra distribución posible, aún más representativa para la comprensión de la estructura social del Antiguo Régimen, es la que nos permite adentrarnos en la compleja geografía jurisdiccional te ia Asturias del siglo xvirr. La división administrativa del Principaço, aun siendo una de las provincias de estructura más homogénea, refleja la diversidad característica del Antiguo Régimen. Exceptuando la capital, que, al igual que la mayor parte de las del país, tenía la condición de ciudad realenga, el resto del territorio se distribuye en las cuatro categorías de concejos (61), cotos (81), jurisdicciones (18) y lugares (6), según puede reconstruirse de los testimonios complementarios de Miñano y Canga Argüelles.

Coronando el sistema administrativo aparece la Junta General del Principado, que representaba al territorio, celaba el respeto de sus fueros frente a los funcionarios de la corona y tenía como medio coactivo la facultad de conceder o negar los subsidios extraordinarios que se solicitasen del Principado, de cuya distribución entre los concejos se encargaban igualmente según la fórmula del encabezamiento. Constituían la Junta los representantes de los lugares de población, aunque ni el sistema que en cada uno de ellos se utilizaba para designarlos ni su participación en las decisiones de la Junta fuesen homogéneos. De acuerdo con la Ordenanza de Hernando de la Vega, que rigió de fines del siglo xv a comienzos del xix, citada por Alvarez Gendín, formaban la Junta con carácter permanente 26 concejos realengos y 24 jurisdicciones de abadengo u obispalía, muchos de los cuales habían pasado a ser concejos realengos en el siglo xvinI. ${ }^{3}$ En cualquier caso no parece que existiesen en ningún momento una representación universal de los concejos ni siquiera realengos, del mismo modo que no todos los procuradores disfrutaban de un peso igual en las decisiones de la Junta. Los concejos realengos tenían voto entero, en tanto las jurisdicciones señoriales sólo tenían un tercio, y el total de sus votos no podía sumar más del tercio del total.

Este esquema general había experimentado numerosas transforma-

(3) Prólogo a las Actas de las Juntas y Diputaciones del Principado de Asturias. 
ciones para el momento final del Antiguo Régimen. Así los concejos de Cabranes, Caravia, Corvera aparecen en Miñano con voto entero en las Juntas. Concejos como el de Morcín y Santo Adriano, que a finales del XVIII aparecen como realengos, figuran, sin embargo, reducidos a su originario tercio de voto, propio de su anterior condición señorial.

El sistema electoral seguido para la designación de procuradores depende del sistema local de gobierno, el cual presenta una enorme variedad de fórmulas, que a su vez nos enfrentan con la fundamental separación entre la Asturias realenga y la señorial. Integran la primera 45 concejos, 3 jurisdicciones, 12 cotos, una ciudad y 4 lugares. Los datos de Canga Argüelles, incompletos, aunque aproximados, dan las siguientes cifras de población:

\begin{tabular}{|c|c|}
\hline 1.716 & 15.636 vecinos $^{4}$ \\
\hline .797 & 264.268 habitantes \\
\hline & 271.595 \\
\hline
\end{tabular}

Los lugares señoriales reunían 16 concejos, equivalentes a un 26,2\% del total de esta fundamental cinrcunscripción administrativa asturiana, 5 jurisdicciones, 69 cotos $(85,1 \%), 2$ lugares, y 17 señoríos eclesiásticos, entre ellos el condado de Noreña. A pesar de la superioridad de lugares de población señorial, el número de sus habitantes es muy inferior a lo que el dato anterior induce a creer. Las cifras de Canga Argüelles, mucho más incompletas que en el caso anterior, por cuanto no recogen prácticamente más que la población de los concejos, son las siguientes:
1.716
3.689 vecinos
1.797
58.183 habitantes
1.802
56.150 habitantes ${ }^{5}$
Miñano.
62.425 habitantes $^{6}$

Aun aceptando la inexactitud e imprecisión previsible en estos datos, se descubre la desproporción entre lugares de población y número de habitantes. Mientras de los primeros hay 110 señoriales, equivalentes a un $62 \%$, frente a 65 realengos, el número de asturianos que caen bajo la jurisdicción señorial se sitúa alrededor del 20\% del total del Principado, circunstancia decisiva a la hora de estimar la verdadera importancia del sistema señorial.

(4) Para esta fecha sus datos dejan muchos blancos.

(5) Las diferencias con las cifras totales del censo se debe a los blancos dejados por Canga Argüelles en su relación y para las clos últimas fechas la variación no llega a un 10\% del total, por lo que puede concederse a estos datos un claro valor indicativo.

(6) Sumando los datos de cada uno de los lugares de señorío, cuya población recoge, aunque no completa en su Diccionario. Cf. Ap. 1. 
La mayor parte de los señoríos pertenecen a titulares laicos. Entre ellos, el marqués de Valdecarzana es con mucho el más importante, al tener bajo su jurisdicción una decena de cotos y jurisdicciones con una población de 4.676 habitantes, sin incluir en ella los pertenecientes al coto de Valdecarzana, del que no hemos podido encontrar el número de sus pobladores. En orden decreciente por el número de señoríos siguen al anterior la ciudad de Oviedo con tres concejos y 3 cotos, el conde de Nava con 4 cotos, el obispo de Oviedo señor del Condado de Noreña y otros dos cotos. Los restantes señores son en su inmensa mayoría titulares de un único territorio.?

Los monasterios son señoríos jurisdiccionales de 9 cotos, en los que generalmente se encuentra enclavada la comunidad, y disfrutan de otras propiedades en el Principado, entre las que destacan los pozos salmoneros. El monasterio cisterciense de Villanueva de Oscos tenía en la aldea de Tío, parroquia de Santa Leocadia de Illano, y concejo de este nombre, unos de los pescales más famosos del río Navia. Los dominicos de Oviedo tenían otro en la confluencia del Nalón y Lena, en el concejo de Ribera de Arriba.

En la generalizada y constante lucha de los pueblos contra sus señores jurisdiccionales, Asturias ofrece una larga serie de concejos y cotos que consiguieron independizarse jurisdiccionalmente de sus señoríos, aunque por el momento no conozcamos las condiciones económicas en que aceptaron éstos la renuncia a sus prerrogativas. De este modo 16 centros de población, de los cuales 10 eran concejos, habían conquistado su independencia y en ellos la jurisdicción se ejercía por sus vecinos.

El proceso de independencia que el dato anterior implica pudiera inducir a error, por cuanto de hecho la población asturiana tanto señorial como realenga distaba mucho de ser libre mediante un régimen autónomo o merced a una dependencia directa de la corona. El caso de mayor rigor señorial que conocemos es el del coto de Villoria, de la jurisdicción de Campo Sagrado, quien lo perdió a fines del siglo xviıI o comienzos del XIX, y cuyos 800 habitantes venían obligados a rendir vasallaje a su señor, quien mantuvo a la entrada de la jurisdicción la horca y la picota como símbolo de sus facultades. Junto a la Asturias señorial los concejos y cotos realengos se gobiernan según sistemas de una fabulosa diversidad, utilizando fórmulas que van desde una total democracia a una independencia casi familiar, siendo mayoría los centros de población en que el poder real residía en manos de un reducido grupo de vecinos.

(7) Cf. Ap, 2 . 


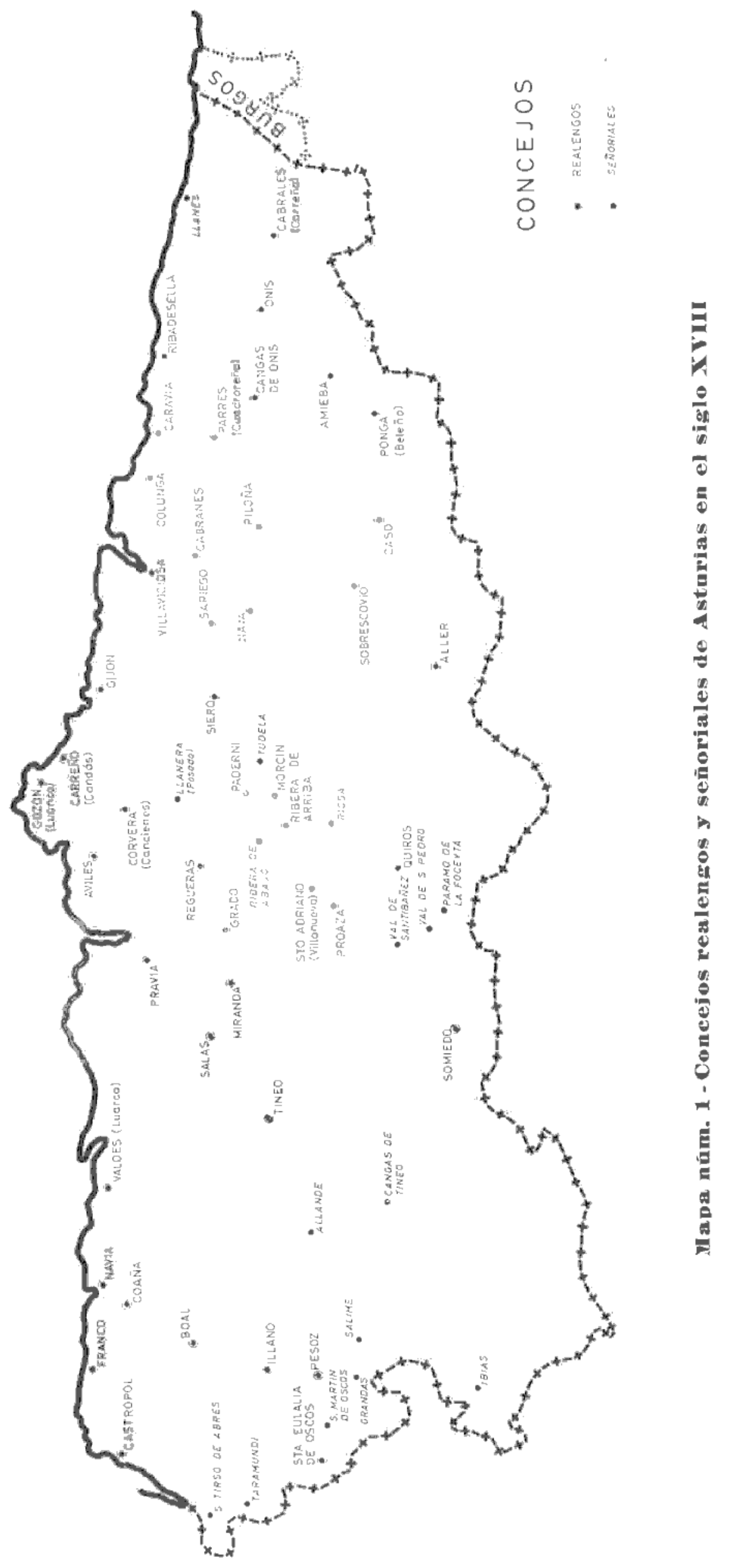


El concejo de Carreño constituye un ejemplo de máxima participación del pueblo en el gobierno a través de un sistema plenamente representativo. "A principios de año - dice Miñano- hay una Junta General de todo el concejo, con asistencia de los vecinos que quieren concurrir, en la Rebolleda o Rebollada, monte raso y despoblado de Logrezana, para dar la posesión al procurador general y para residenciar a justicias y oficios del año anterior, acto que concluye con comida y bebida para todos.» En el otro extremo figuran concejos como el de Aller, gobernado por 2 jueces nobles y varios regidores perpetuos. Entre ambas fórmulas se extiende una amplia gama de posibilidades caracterizadas por el mayor o menor número de miembros del ayuntamiento encargados de la elección, así como de la condición electiva o hereditaria de sus componentes. Así, mientras el concejo de Ponga se gobierna por un municipio integrado por 5 regidores perpetuos y un alférez mayor, que designan un juez noble y otro plebeyo, el de Piloña funciona con un sistema de gran complejidad. «Se gobierna por 24 regidores, los cuales nombran un juez primero noble, un segundo de la clase de labradores y un procurador general, personero del común, cuatro diputados que son individuos del cuerpo con voto, alférez mayor, alcalde mayor, alguacil mayor y un depositario del concejo, con un montero mayor de la clase de los nobles.»

En líneas generales puede afirmarse que las funciones de gobierno local a través de los procuradores elegidos por los ayuntamientos de la Junta del Principado, refleja una evidente señorialización a través de la doble fórmula de los regidores perpetuos, propietarios del cargo posiblemente por compra, y de los jueces nobles, que tienen siempre una destacada posición entre los funcionarios municipales.

Existen finalmente casos más complejos cuando existía dependencia de un lugar respecto de otro. Tal ocurría en Avilés, concejo gobernado por regidores perpetuos, que tenían sus empleos con carácter de hereditarios en virtud de títulos conferidos por la real cámara, y designaban anualmente hasta siete funcionarios para desempeñar los cargos municipales. Del concejo de Avilés dependían Illas y Castrillón, lugares que a semejanza de aquél tenían sus propios ayuntamientos de regidores perpetuos, que actuaban con independencia para los repartimientos y encabezamientos, cuya cuota fijaban los del primero. Igualmente la justicia avilesina desempeñaba funciones de segunda instancia y se hacía coincidir los nombramientos de jueces de ambos lugares con el de los de Avilés, que tenía lugar el primer día del año, momento en que los primeros prestaban juramento a los segundos. "Hecho este acto de jurisdicción por los jueces de Avilés, los dos nuevos alcaldes presentan 
vino y bizcochos que llaman el yantar, sobre lo cual no se les permite variación ni disimulo.»

Las diferencias entre concejos realengos no sólo se reducían a sus respectivos sistemas de gobierno, sino que subsistían diversos privilegios, que hacian sumamente variable la condición de los vecinos. El concejo de Cabrales estaba exento del pago de alcabalas, mientras los de Cabranes y Nava disfrutaban para su gobierno del fuero de Benavente. El de Caso tenía kel privilegio de poder apacentar sus ganados y recuas en cualesquiera pastos del reino que estén abiertos para los ganados de los vecinos de los respectivos pueblos sin pagar cosa alguna y la franquicia de no pagar barcaje, peaje, portazgo ni otras gabelas». El de Ponga tenía concedidos por Enrique III y renovados por sus sucesores hasta Carlos IV los privilegios de «que guardando panes, viñas y dehesas reales puedan pastar con sus ganados, paciendo hierbas y bebiendo agua por todo el reino», así como el de estar "exentos de todo portazgo y yerbazgo en todas las ciudades, villas y lugares del reino."

La población de Asturias, organizada social y políticamente en forma totalmente heterogénea, presenta desde el punto de vista de su actividad económica una estructura mucho menos diferenciada, debido al predominio de las actividades agrícolas, cuyo valor ascendía al 93,5\% del total de la producción del Principado. Al comienzo del pasado siglo Asturias conserva una estructura agraria dominante, a pesar de lo cual sólo consigue cubrir la mitad de las necesidades de su población y ganaderia. Frente a la agricultura y ganadería, la industria y comercio ocupan una parte mínima de la población y apenas si ha comenzado muy levemente el desarrollo de la industria extractiva, como lo revela el hecho de que el valor del carbón obtenido a fines de la centuria no alcance el del mijo.

La partida más importante de la renta del Principado procedía del maíz, según el censo de 1799 , con un valor bruto de 30,6 millones de reales, de Ia escanda con 10,9, por cuanto el valor de la ganadería, especialmente vacuna, incluye el valor de los totales (capital y renta) y no el de las reses sacrificadas o exportadas, que debería ser muy inferior a los 26 millones en que se cifra aquél. La tercera fuente de ingresos del Principado, procede de la fabricación de tejidos de inferior calidad, cuyo valor se calcula en 2,7 millones. El cultivo del maí, escanda, trigo y centeno, producciones agxícolas fundamentales del Principado, se practica en todo el territorio, aunque los núcleos harineros, fuesen los Conce- 


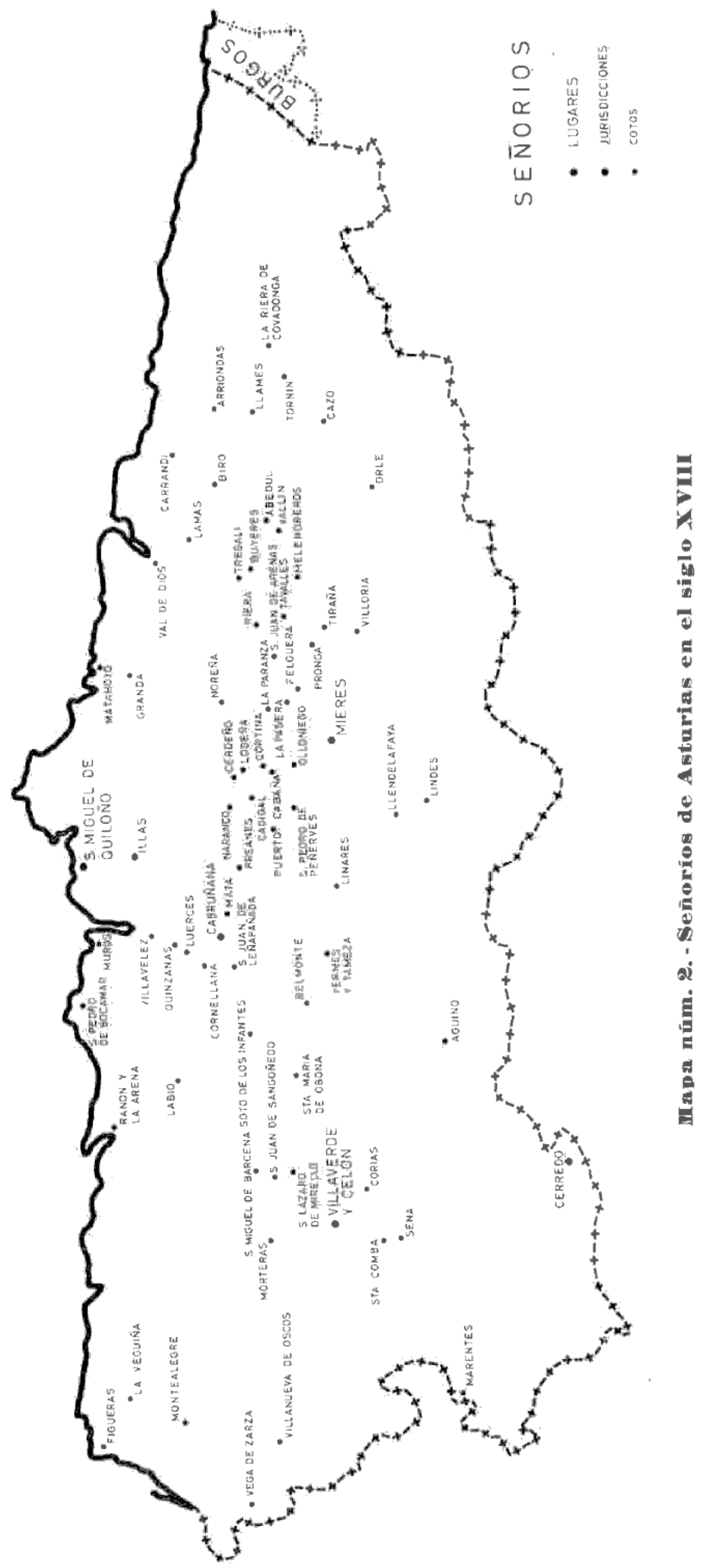


jos de Grado y Siero con 82 y 60 molinos respectivamente, seguidos por los de Carreño, Proaza y Santa Eulalia entre los realengos y el de Llanes entre los señoriales. La estructura de la propiedad agraria, muy dividida según los testimonios unánimes de los contemporáneos, determina la existencia de gran número de arrendatarios, cuya condición contractual es frecuentemente denunciada como causa de una insuficiente productividad. Miñano critica el mal cultivo de la tierra en el concejo de Piloña, y hablando del de Reguera, dice: "En un distrito donde es desigual y monstruosa la división de bienes, donde hay muchos inquilinos o renteros y casi ningún pequeño propietario, muchos montes comunes y mucha libertad para encerrarlos, no puede prosperar la agricultura." Peor resulta la situación del superpoblado concejo de Llamera, cuyos vecinos, - en su mayor parte hidalgos y labradores, generalmente muy pobres, porque casi todos son arrendatarios y traen los arriendos muy subidosson más en número que los que el suelo según el estado actual de la agricultura puede mantener.» El interés de los propietarios por una mayor rentabilidad inmediata es considerado responsable de la ruina de casas, hórreos y villas al no preocuparse sino de cobrar el canon del arrendamiento.

La ganadería, fundamentalmente vacuno y caballar, se encuentra muy extendida, con territorios como los concejos de Nava y Proaza cuya riqueza en pastos permitía se mantuviesen en su término gran número de cabezas de ganado de todas especies, pues sólo en el primero se calculaba una cifra superior a las 20.000 cabezas.

Las materias primas vegetales - lino y cáñamo- producidas en el país resultaban insuficientes para cubrir la capacidad de los telares. Junto con la lana constituían la base de una primitiva y rudimentaria industria textil con un carácter enteramente artesanal y cuyos instrumentos, el telar y el batán, estaban extendidos, hasta tal punto que el censo de 1799 hará coincidir el número de obradores - 1.500 de lino y cáñamo, 480 de lana- con el de operarios. La producción salida de estas máquinas es de ínfima calidad, reflejo a su vez de una manipulación inmediata del producto natural y en consecuencia su único mercado es el de la propia población asturiana.

Otra industria derivada es la de los curtidos, cuyos principales centros estaban en Oviedo, Gijón, Navia y los territorios señoriales del concejo de Cangas de Tineo y condado de Noreña. Esta última villa, cuya población se aproximaba a los 2.000 habitantes, estaba dedicada fundamentalmente a este tipo de actividad, como lo revela el hecho de que se contasen en ella - según Miñano- hasta 800 oficiales de obra prima. 
La producción del Principado cubría ampliamente sus necesidades y podía exportar un tercio del total, que se colocaba en gran parte en el vecino reino de León.

La estructura económica del Principado, apenas si comienza a descubrir las posibilidades que en el siglo XIx había de darle la explotación de sus recursos carboníferos, cuya extracción, limitada a 90.000 quintales en 1799, apenas anunciaba el desarrollo posterior. Es el momento de tránsito de la utilización del carbón vegetal, cada día más difícil de conseguir: "la corta excesiva de árboles, las quemas continuas de leña para carbonizarla y el descuido de no repoblar los montes contribuyó a dar sumo precio al carbón vegetal.» Por tal motivo Miñano insistirá en la necesidad de explotar «el mineral de carbón de piedra que se halla en los montes y del cual hasta ahora no se hizo uso alguno». Así criticará a los vecinos del concejo de Piloña, que, al tiempo que cultivan mal la tierra, no se cuidan de explotar el carbón mineral en que abunda el territorio. Los centros más importantes de explotación carbonífera se encontraban en los concejos de Pravia (minas de Langreo) y Siero.

El carbón mineral, exceptuando el que se destinaba a los grandes arsenales del Ferrol y Cartagena, era utilizado como combustible en una incipiente industria siderometalúrgica que refleja aún la inicial situación en que el hierro viajaba en busca del carbón. El entusiasmo de Miñano por la mina de hierro de Castañedo, en el concejo de Santo Adriano, ${ }^{8}$ no había servido, sin embargo, a dar al Principado la autonomía en este mineral. Las ferrerías asturianas venían surtiéndose del mineral vizcaíno de Somorrostro, que servía a producir baterías de cocina, clavazón, armas y municiones. Las dimensiones de estos talleres eran también aquí muy próximas a la pura artesanía, con la excepción de las fábricas de armas de Oviedo y Trubia, y el total de su producción resultaba insignificante dentro del conjunto del país.

Junto con la loza y el hierro Asturias tuvo en el concejo de Corvera dos fábricas de cobre que a finales de siglo elaboraban más de 35.000 libras de metal, cifra rebasada en etapas anteriores, en que se alcanzó el medio centenar. Hasta fines del siglo XvirI se utilizó en sus fraguas carbón vegetal e importaban el mineral de Hamburgo, que hubieron de sustituir por el peruano luego que la Revolución francesa cortó aquella línea de abastecimiento, lo que a su vez obligó a la utilización de hornos de reverbero.

(8) "No hay en Europa mina alguna conocida que tenga la riqueza, las excelentes cualidades, Ia situación, las proporciones para explotar a cielo descubierto, como una gran cantera, a muy poca costa, ni que ofrezca tantas utilidades como la de Castañedo.» 
La participación de Asturias en el sistema económico-nacional refleja las consecuencias de una gran densidad de población unida a un insuficiente desarrollo industrial. El Principado es la quinta provincia española atendiendo a la densidad de población. Cuenta en 1799 con 38,2 habitantes por $\mathrm{Km}^{2}$, frente a una media nacional de 22,1. El producto provincial bruto representa el 1,52\% del nacional, en tanto que su población corresponde, según vimos, al 3,4\%. La razón de tal disparidad reside, en un primer análisis, en la doble circunstancia de una agricultura cuya productividad resulta limitada, tanto por las condiciones geográficas de la región, inadecuadas para la producción de aquellas mercancías del más alto valor mecantil, como por el régimen jurídico de la propiedad, caracterizada por la fragmentación de parcelas. La renta que la agricultura deficitaria no produce no resulta compensada con la de la industria, que no representa sino un $6,32 \%$ del producto provincial. El Principado sólo tiene tras de sí seís provincias (Extremadura, Cuenca, Toro, Zamora y las Nuevas Poblaciones) con niveles de industrialización inferiores al suyo. La unión de ambos factores determina el hecho de que Asturias ocupe el último puesto en la clasificación provincial cuando se toma en cuenta la renta per capita.

EI Principado, con 264 reales por cabeza, constituye una típica zona depresiva y junto con Guipúzcoa (303 reales) y Galicia ( 324 reales) proporcionan la mayor parte de la emigración interior de la época.

Por el momento no resulta posible la extensión de este análisis al interior del Principado, estableciendo la relación existente entre los distintos concejos, así como la proporción en que se distribuye la riqueza entre la Asturias realenga y la señorial. Como un tímido anticipo podemos señalar como los concejos más ricos, en cuanto mayores contribuyentes, los de Villaviciosa, Cangas de Tineo, Avilés y Siero, pero es éste un trabajo que requiere un más detenido estudio de los encabezamientos.

Las páginas precedentes, de cuya necesidad de revisión somos plenamente conscientes, tienen más la pretensión de señalar un camino, que de dar una respuesta. Dadas las fuentes históricas de que disponemos y el nivel técnico alcanzado por nuestra ciencia es posible adentrarse mucho más profundamente en el conocimiento de las realidades de base de la vida social española de épocas pretéritas. Para el siglo xviri y Asturias, objeto de esta comunicación sería posible no ya los mapas que ilustran estas páginas sino una precisa división geográfica, no sólo de la división administrativa, sino también de la eclesiástica. Del mismo modo podría determinarse una más precisa y cuantificada presentación de los factores económicos, lo que a su vez nos permitirá comprender y explicar movi- 
mientos y circunstancias sociales que trasladadas a escala nacional serán decisivas para la comprensión de nuestra historia.

\section{Población realenga de Asturias}

Aller (C)

Amieba (C)

Avilés (C), Illas ( $\mathrm{J}$ ) y Castrillón

Baiña y Lozedo

Beana (C)

Boal (C)

Boymoro

Cabrales (C)

Cabranes (C)

Cangas de Onís (C)

Candamo (J)

Caravia (C)

Carreño (C)

Caso (C)

Castañedo

Castropol (C)

Coaña (C)

Corbera (C)

Colunga (C)

Colombiello y Rebolleda

Franco (C)

Fuentes

Gijón (C)

Gozón (C)

Grado (C)

Gua y Caunedo

Illano (C)

Illas $(\mathrm{J}) \mathrm{c} /$. Avilés

Leitariegos

Mieres del Camino (J)

Miranda (C)

Morcín

Nava (C)

Navia (C)

C. Oviedo

Onís (C)
Vecinos

\begin{tabular}{|c|c|c|c|}
\hline 1716 & 1797 & 1802 & 1826 \\
\hline 513 & 6.808 & 6.762 & \\
\hline 140 & 1.830 & 1.789 & 2.228 \\
\hline 404 & 9.881 & 9.893 & \\
\hline
\end{tabular}

$4.881 \quad 4.772 \quad 3.656$

234

\subsection{3}

2.917

186

4.851

2.951

3.030

286

4.851

$36 \quad 540$

$213 \quad 5.291$

30

$3.179 \quad 3.188$

$4.834 \quad 4.800$

$2.226 \quad 11.885$

3.096

555

650

4.928

766

3.096
98 $\quad 3.598$

$332 \quad 5.092$

2.850

2.686

4.507

$4.463 \quad 4.665$

280

$11.106 \quad 13.272$

693

6.794

6.893

15.729

16.925

1.490

1.568

1.622

1.500

$\begin{array}{crr} & 326 & 337 \\ 817 & 2.635 & 2.620 \\ \text { con Lena } & & \\ & \end{array}$

136

4.781

4.602

1.631

4.671

$252 \quad 5.055$

6.967

630

6.931

12.525

772

12.685

1.287
3.613

2.405

10.476 
Paderní (C)

L. Pajares del Puerto ..............................

Parres (C)

Peñaflor

Pesoz (C)

Piloña $(\mathrm{C})$

Ponga (C)

Pravia (C)

Priandi

Proaza (C)

Regueras (C)

Ribadesella (C)

Ribera de Arriba (C)

Salas (C)

Sariego (C)

L. San Martín de Laspra

L. San Román de Naveces

L. Santiago del Monte

Santa Eulalia de Oscos (C)

Santa María de Bendones

Santo Adriano (C)

Siero (C)

Sobrescovio (C)

Somiedo (C)

Suero

Tineo (C)

Valdés (C)

Villaviciosa (C)
Quirós (C)

\begin{tabular}{|c|c|c|c|}
\hline Vecinos & \multirow[b]{2}{*}{1797} & \multirow[b]{2}{*}{1802} & \multirow[b]{2}{*}{1826} \\
\hline 1716 & & & \\
\hline 14 & 345 & 358 & 259 \\
\hline 13 & 237 & 251 & 196 \\
\hline 267 & 5.616 & 5.616 & 3.400 \\
\hline 19 & 863 & 876 & 880 \\
\hline 665 & 11.449 & 10.406 & \\
\hline 140 & 2.150 & 2.445 & 2.250 \\
\hline 759 & 18.196 & 18.767 & \\
\hline 14 & & & \\
\hline 136 & 2.063 & 1.530 & 2.387 \\
\hline 266 & 3.311 & 3.564 & \\
\hline 168 & & 2.965 & \\
\hline 318 & 5.558 & 5.266 & \\
\hline 100 & 1.404 & 1.656 & \\
\hline 462 & 10.171 & 10.354 & \\
\hline \multirow[t]{2}{*}{66} & 776 & 826 & \\
\hline & 1.794 & 1.755 & 945 \\
\hline 8 & 120 & 127 & \\
\hline 98 & 1.410 & 1.265 & \\
\hline 576 & 12.761 & 12.520 & \\
\hline 565 & 1.899 & 1.899 & 1.606 \\
\hline 252 & 3.295 & 3.506 & \\
\hline 773 & 11.403 & 11.456 & \\
\hline 700 & 16.119 & 16.031 & \\
\hline 716 & 15.258 & 15.282 & 14.124 \\
\hline 15.636 & 264.268 & 271.595 & \\
\hline
\end{tabular}

Población señorial de Asturias

Abedul

Aguin̄o y Pertunes, con Essa ...........................

Allande (C)

Arriondas

Belmonte (S. E.)

\begin{tabular}{|c|c|c|c|}
\hline Vecinos & \multirow[b]{2}{*}{1797} & \multirow[b]{2}{*}{1802} & \multirow[b]{2}{*}{1826} \\
\hline 1716 & & & \\
\hline 8 & & & 155 \\
\hline 28 & & & 250 \\
\hline & & & 7.021 \\
\hline 8 & 2.905 & & 90 \\
\hline 42 & & & 519 \\
\hline
\end{tabular}


Biao

Buyeres

Vecinos

Cabaña

Cabruñana (J) …..............................

Cagiga

\begin{tabular}{|c|c|c|c|}
\hline 1716 & 1797 & 1802 & 1826 \\
\hline \multirow[t]{3}{*}{9} & & & 291 \\
\hline & & & 83 \\
\hline & & & $\begin{array}{l}73 \\
29\end{array}$ \\
\hline 15 & & & 29 \\
\hline $\begin{array}{r}10 \\
799\end{array}$ & 15.780 & 15.762 & $\begin{array}{r}221 \\
15.889\end{array}$ \\
\hline 22 & & & 280 \\
\hline \multirow[t]{2}{*}{313} & 4.278 & 4.265 & 560 \\
\hline & & & 36 \\
\hline \multirow{2}{*}{$\begin{array}{l}98 \\
17\end{array}$} & & & 147 \\
\hline & & & \\
\hline \multirow[t]{4}{*}{56} & & & 1.000 \\
\hline & & & 581 \\
\hline & & & 113 \\
\hline & & & 981 \\
\hline
\end{tabular}

Camas (S. E.) …................................. 15

Cangas de Tineo (C)

Carrandi

Caro

Cerdeño

Cerredo y Degaña $(J)$

Corias (S. E.)

Cornellana (S. E.)

Cortina

(S. E.)

Figueras

981

Granda

Grandas de Salime (C)

Yernes y Tamera

338

Ibias (C)

2.500
65
4.350

2.566

1.898

52

177

658

651

658

La Veguiña

Lavio

51

6

1.063

La Paranza

La Pasera (S. E.)

La Riera de Covadonga (S. E.)

Linares

Lindes (S. E.)

Lodeña

4.350

4.274

\section{(Ludeña)}

Luerces

Llamera (C)

Llames (S. E.)

Llanes (C)

Lendelafaya (S. E.)

Marentes

Mata

Melendreros

Morteras

Montealegre

Muros

Naranco

Natahoyo

Noreña, condado (S. E.)

Olloniego (J)

Orlé

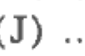

Páramo de la Forceya (C) 
Porreño

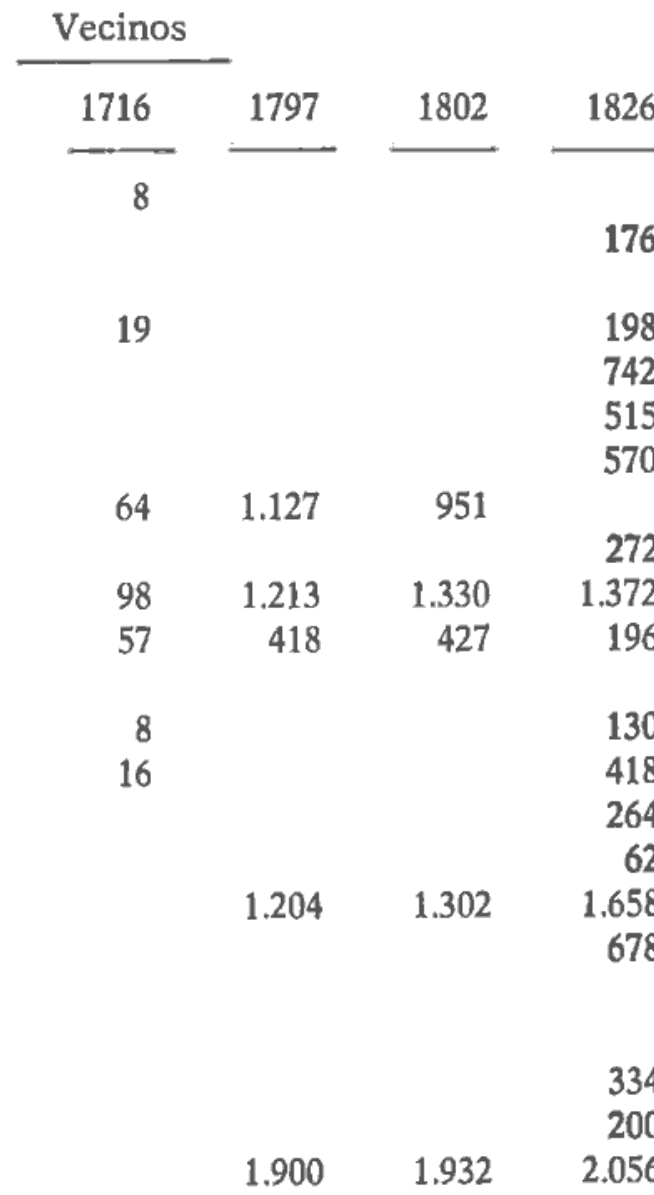

(Priañes)

Pronga

742

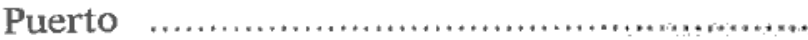

515

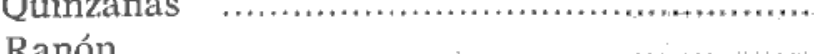

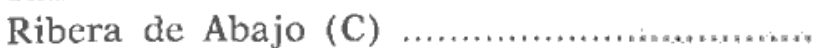

Riera

Riosa (C)

Salime (C)

San Bartolomé (S. E.)

San Juan de Leñapañada (S. E.) ...................

San Juan de Sangoñedo

San Lázaro de Mirallo

San Martín de Oscos (C)

San Miguel de Bárcena

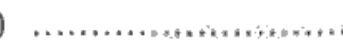

L. San Miguel de Quiloño

San Pedro de Bocamar

San Pedro de Coalla (J)

334

200

San Pedro de Peñernes

1.900

206

Santuario

Santa Comba

$\begin{array}{rrrr} & & & 206 \\ & & & 600 \\ 49 & & & 594 \\ & & & 706 \\ & & & 306 \\ & 1.964 & 1.964 & 2.578 \\ 96 & & & 998 \\ & & & \\ & & & 172 \\ 73 & 1.478 & 1.478 & \end{array}$

Tudela (C)

Valcarce

(1)

Valdecarzana (J)

Valdediós (S. E.)

46

Val de San Pedro (C)

Val de Santibáñez

(C)

Vallín

Vega de Zarza

Villavélez

L. Villaverde y Celón

Villanueva de Oscos (S. E.)

\begin{tabular}{rrrr} 
& & & 381 \\
65 & 1.033 & 1.063 & 827 \\
& & & 1.530 \\
\hline 3.689 & 58.185 & 56.150 &
\end{tabular}




\section{Titulares de los señoríos asturianos}

Marqués de Valdecarzana.-Aquiño, Cabruñana ( $\mathrm{J}$ ), Luerces, Mata, Muros, Quinzanas, Ranón, San Pedro de Coalla (J), Soto de los Infantes, Valdecarzana.

Por los vecinos.-Abedul, Grandas (C), Yernes, Lavio, Llanes (C), Páramo de la Forceya (C), Pronga, Riera, Riosa (C), Salime (C), San Martín de Oscos (C), Taramundi (C), Tudela (C), Val de San Pedro (C), Val de Santibáñez (C), Villavélez.

Por el conde de Peñalba.-Allande (C), Cazo.

Por don José de Omaña.-Arriondas.

Monasterios.-Belmonte, Camas, Val de Dios (monasterio de Val de Dios), Corias, Cornellana, Llames, San Bartolomé (monasterio de San Pelayo), Santa María de Obona (Abad de Obona), Villanueva de Oscos.

Conde da Nava.-Biao, Melendreros, Tiraña, Vallín.

Por S. M.-Cabaña.

Ciudad de Oviedo.-Cagigal, Cerdeño, Llamera (C), Naranco, Paderni (C. Realengo), Ribera de Abajo (C).

Por la villa.-Cangas de Tineo (C).

Bernardo de Junco.-Carrandi.

Conde de Toreno.-Cerredo (J).

Fernando Portocarrero.-Cortina.

Obispo de Oviedo.-Felguera, La Pasera, Noreña (condado).

Juan Pardo.-Figueras.

Pedro Valdés.-Granda.

Por sus parroquias.-Ivias (C), Navia (C. Realengo).

Lorenzo Valderrein.-La Veguiña.

Diego Argüelles.-La Paranza.

Por la Colegiata.-La Riera de Covadonga.

Joaquin Velarde.-Linares.

Diego Castañón.-Tornín, Tresali.

Manuel Bermúdez.-Vega de la Zarza.

Baltasar de Cienfuegos.-L. Villaverde y Celón.

Marqués de Camposagrado.-Villoria.

Hospital de Arbas.-Lindes.

Fernando Valdés Sorribos.-Lodeña.

Deán de Oviedo.-Llendelafaya.

Bartolomé Rodón.-Marentes.

Por la jurisdicción.-Mieres (J).

Marqués de Tineo.-Morteras.

Jacinto Vallador.-Montealegre. 
Marqués de San Esteban.-Natahoyo.

Tomás de Benavides,-Olloniego (J).

José de Hevia Caso--Orlé.

Diego de Hevia.-Porreño.

Ramón de Jove.-Preanes.

Marqués de Santa Cruz.-Puerto.

Comendador de Malta.-San Juan de Arenas, San Juan de Leñapañada.

Carlos Llamas,-San Juan de Sangoñedo.

Conde de Miranda.-Sán Lázaro de Mirello.

Mayorazgo de Tineo.-San Miguel de Bárcena.

Conde de Castrillón.-L. S. Miguel de Quíloño.

Arias de Omaña,-S. Pedro de Boca de Mar, Valcarce.

José Argitello Quiñones,-San Pedro te Peñerves.

Conde de Altamira.-S. Tirso de Abres (C).

Joaquin Pardo y Andrade.-Santa Comba.

Marqués de Ferrera.-Sena.

Carlos Valvidares.-Tavalles. 